\title{
EFFECT OF RE-PRESSING OF LITHIUM DISILICATE CERAMIC WITH DIFFERENT WEIGHT PERCENTAGES ON COLOUR, TRANSLUCENCY AND SHEAR BOND STRENGTH TO VENEERING MATERIAL
}

\author{
Shereen Kotb Salem* and Mohammed Moustafa Shalaby**
}

\begin{abstract}
Aim of the study: is to investigate effect of re-pressing of Lithium disilicate ceramic with different weight percentages on colour, translucency and bond strength with veneering material.

Materials \& Methods: Thirty discs were constructed and divided according to the weight percentage of newly pressed and repressed ceramic. Group 1 samples were $100 \%$ new ceramics. Group 2 discs were 75\% new and 25\% repressed ceramic. Group 3 samples were 50\% new and $50 \%$ repressed ceramic. Group 4 samples were 25\% new and 75\% repressed ceramic. Group 5 discs were $100 \%$ repressed ones. One sample from each group was randomly selected for SEM test. The remaining discs in each group ( 5 samples) were used to test colour and translucency, then these samples were veneered with porcelain and subjected to shear bond strength test.
\end{abstract}

Results: The results showed that $\Delta \mathrm{E}$ of the tested groups were in the clinical accepted range except the $100 \%$ re-pressed group. Also, the results showed that there was no significant difference between all tested groups as related to translucency. As regard bond strength, there was no significant difference between $100 \%$ new group and the $75 \%$ new $+25 \%$ re-pressed group. Also, no significant difference was recorded between the $75 \%$ new $+25 \%$ re-pressed group and the $50 \%$ new $+50 \%$ re-pressed group. On the other hand, there was a significant difference between the $100 \%$ new group and the $50 \%$ new $+50 \%$ re-pressed group which was also different than the $25 \%$ new $+75 \%$ re-pressed group. Finally, there was a significant difference between the $100 \%$ re-pressed group and the $25 \%$ new $+75 \%$ re-pressed group.

Conclusions: The mix of new ingot with repressed ceramic are in the clinical acceptance range as regard $\Delta \mathrm{E}$. The $100 \%$ re-pressing ceramic can affect the final colour. Ceramic repressing has no significant effect on translucency. Weight percent of repressed ceramic has a direct effect upon bond strength to veneering material as increasing the percentage of repressed ceramic led to a decrease of bond strength values.

KEYWORDS: Colour, IPS e.max Press, microstructure, Repress, Shear bond strength, translucency, veneer.

* Associate Professor of Fixed Prosthodontics, Faculty of Dentistry, October 6 University.

** Lecturer of Fixed Prosthodontics, Faculty of Dentistry, Minia University. 


\section{INTRODUCTION}

Absence of metallic substructure in all ceramic restorations rendered them to have high translucency and excellent esthetics. ${ }^{(1)}$ This is combined with reliability and long term success. Accordingly, their high demand led to a notable development and evolution of all-ceramic materials and processing techniques. ${ }^{(2,3)}$

Nowadays, the simplicity of heat pressing technique makes it a very common. It has the advantage of producing ceramic restorations with better crystalline dispersion and less porosities within the glass matrix as well as better marginal adaptation compared to other techniques. ${ }^{(4-7)}$ Pressable ceramics are presented in the form of ingots to be pressed under pressure into a mold using an alumina plunger in a pneumatic press furnace. ${ }^{(1)}$

IPS Empress was the first heat-pressed glass ceramic and leucite $\left(\mathrm{SiO}_{2}, \mathrm{Al}_{2} \mathrm{O} 3,4 \mathrm{~K}_{2} \mathrm{O}\right)$ is the main crystalline phase in this system..$^{(4,8,9)}$ IPS e.max Press material replaced IPS Empress 2 due to its improved mechanical properties and higher translucency (Ivoclar Vivadent, IPS e.max Press Scientific Documentation, 2011). Its microstructure consists of $70 \%$ lithium disilicate crystals embedded in a glassy matrix. IPS e.max Press is supplied in 4 different opacities and/or translucencies in 2 sizes: a small ingot that weighs $3.2 \mathrm{gm}$ and a larger ingot that weighs $6.1 \mathrm{gm}^{(10)}$ Selection is done according to the requirements of each clinical case. It is more cost effective to press more than one restoration from the same ingot at the same time instead of discarding the remaining sprue and button portions. (1) Usually, this is not possible resulting in a large amount of leftover material. That's why the idea of reusing leftover material by repressing was raised and supported by many researchers. ${ }^{(3,11,12)}$ Concerns about mechanical properties of the re-used material for clinical use were presented. Few studies were carried by researchers to investigate the mechanical and microstructural properties of repressed ceramics evaluating the biaxial flexural strength..$^{(3,6,12)}$
As the remaining ceramic may not be sufficient for pressing a new restoration and may need to be mixed with a new ingot material.Salem and Shalaby (2019) $^{(13)}$, carried out a research to investigate the effect of repressing IPS e.max Press with different weight percentages on the marginal gap and fracture strength of ceramic crowns. They found an effect of different weight percentages of repressed ceramics on marginal gap as well as fracture strength although all tested groups were clinically accepted. They recorded that different weight percentages of repressed ceramics affected the marginal gap and had a significant effect when it exceeded 50\%. They also concluded that homogeneity of the ceramic structure had a positive effect on fracture strength, as the least fracture strength was recorded for the 50\% new $+50 \%$ repressed ceramic group and it increased significantly as this relation increased towards either the new ingot ceramics or the repressed ceramic. Since there are few data about repressing and only one research about mixing new ceramic ingot with repressed ceramic that examined only marginal gap and fracture strength, it may be mandatory to examine optical properties of repressed ceramics and their mixing in weight percentages with new ceramic material.

Natural teeth or ceramic restorations colour depends on their capacity to modify the colour of incident light. Natural teeth colour results from the combination of light reflected from the enamel surface, and light scattered and reflected by the enamel and dentin. ${ }^{(14)}$ Surface texture, curvature and gloss of an esthetic restoration can modify its colour. These factors may play an important role in modifying the light striking the restoration surface and play an effective role in the appearance of the final restoration ${ }^{(15)}$. Colour change $\Delta \mathrm{E}$ values are determined for three parameters : $\Delta \mathrm{L}^{*}$ which is the change in lightness or darkness, $\Delta \mathrm{a}^{*}$ which is the change in the hue along the red/green scale , $\Delta b^{*}$ which is the change in the hue along the yellow/ blue scale. Several investigators drew the attention 
that differences in $\Delta \mathrm{E}$ values below 3.7 units as matching in the oral environment. ${ }^{(16,17)}$

Teeth are characterized by a variety range of translucency, which can be defined as the slope between transparent and opaque. Increasing translucency of dental ceramics, allows light to go by the surface and is scattered within the body of ceramic. It is well established that increasing ceramics translucency lowers its value because less light returns to the eye, or in other words can affect esthetics due to change of its value. ${ }^{(18)}$

Although lithium disilicate can be used without veneering material but sometimes veneering is needed. Cores and veneering materials are different in their modulus of elasticity, coefficient of thermal expansion (CTE) and behaviour. ${ }^{(19)}$ Researchers reported the formation of strong bonds between cores and veneering material with similar composition due to chemical bond. This draws the attention that any change in microstructure that may occur due to repressing or mixing new ceramic with repressed may affect this bond. ${ }^{(20)}$

The aim of this study is to investigate the effect of repressing IPS e.max Press with different weight percentages on colour, translucency as well as bond strength to veneering material. The hypothesis is that ceramic repressing will affect the three tested parameters. Also, that different percentages of repressed ceramics will have different effect on these three parameters.

\section{MATERIALS AND METHODS}

\section{Factorial Design}

Thirty discs $(10 \mathrm{~mm}$ in diameter and $1.5 \mathrm{~mm}$ in thickness) were constructed. These discs were divided into 5 groups according to the weight percentage of newly pressed \& re-pressed ceramic. Group 1: samples were $100 \%$ new ceramics. Group 2: samples were $75 \%$ new and $25 \%$ repressed ceramic. Group 3: samples were 50\% new and 50\% repressed ceramic. Group 4: samples were 25\% new and $75 \%$ repressed ceramic. Group 5: samples were $100 \%$ repressed ones. One sample from each group was randomly selected for SEM test to study the microstructure of these samples. The remaining discs in each group (5 samples) were used to test colour change and translucency, then these samples were veneered with veneering porcelain and subjected to shear bond strength test.

\section{Samples Construction}

A split copper mold with Teflon ring was manufactured for this study using an industrial lathe machine. The mold was used to standardize the dimensions of the discs and the overlying porcelain. The mold has 2 different diameters $10 \mathrm{~mm}$, and $8 \mathrm{~mm}$. The $10 \mathrm{~mm}$ diameter section had 1.5 thickness, while the $8 \mathrm{~mm}$ diameter part is $2 \mathrm{~mm}$ in height.

\section{Samples construction for colour and translucen- cy tests}

The Teflon ring was placed to secure the 2 pieces of the first split copper mold. The IPS e.max Press discs shade A3 MT (Ivoclar Vivadent, Schaan, Lichtenstein) were produced using lost-wax and heat-pressing techniques. Blue inlay wax was dipped inside the lower part of the copper mold till it is completely filled. The wax was left for 2 minutes to cool. Then the Teflon ring was removed, and the 2 parts were separated for removal of the wax disc. This procedure was repeated 29 times to have 30 wax discs. Sprues formers of the same diameter were attached to these discs. The sprued patterns were weighted using a professional digital table scale (Shenzhen Wei Uxing Trading Co,Ltd.). A special type of phosphate bonded investment IPS PressVest Premium (Ivoclar Vivadent, Schaan, Lichtenstein) was vacuum mixed. The ring containing the sprued wax patterns was filled with the mixed investment on a vibrator. Each ring contains 6 sprued patterns for construction of the samples of each subgroup. The invested ring was gradually preheated for 60 minutes in the burn-out furnace. The heated ring 
was positioned immediately in the pressing furnace (Programat EP3010, Ivoclar Vivadent, Schaan, Lichtenstein). Ceramic ingots were plasticized at $920^{\circ} \mathrm{C}$ and pressed in its softened state into the hollow place in the investment ring by means of a plunger. After pressing, the pressed discs and sprues were weighed to calculate the needed weight of ceramic needed for fabrication of the samples. The sprues were cut . The ceramic that will be repressed was ground to fit in the opening at the top surface of the investment mold. Ceramic material was placed in each pressing cycle according to the desired Wt.\%. ${ }^{(13)}$ All samples were finished using finishing kit (Eve Diapol, Eve Ernst Vetter GmbH Rastatter Str. Pforzheim). One side was polished using the same finishing kit. A glaze layer (IPS Ivocolor glaze (Ivoclar 5 Vivadent, Schaan, Lichtenstein) was painted on the other side of the discs. Then the discs were placed in the porcelain furnace. (Programat P300, Ivoclar Vivadent, Schaan, Lichtenstein), and glazing cycle at $735^{\circ} \mathrm{C}$ was run.

The colour of the discs was measured under black background to detect the $\Delta \mathrm{E}$ and their translucency was measured under white and black background to detect CR (Contrast ratio) using the spectrophotometer (Cary 5000, Agilent Technologies, USA).

\section{Samples construction for shear bond strength test}

After both colour and translucency tests, the discs were placed in the lower part of the mold with the unglazed surface on top. Through the hole in the upper part of the mold, veneering dental porcelain IPS e.max Ceram (Ivoclar Vivadent, Schaan, Lichtenstein) with matched coefficient of thermal expansion is added and condensed. The hole in the upper part of the mold has dimension of $8 \mathrm{~mm}$ thickness, and $2 \mathrm{~mm}$ height. The discs with the overlying porcelain were placed in the porcelain furnace (Programat P300, Ivoclar Vivadent, Schaan, Lichtenstein). for firing of the veneering material according to the manufacturer's instructions. At the end a glazing cycle was performed. Figure (1) shows the finished sample. The discs were imbedded in a container containing chemically set acrylic till complete set. The level of the acrylic was adjusted to allow that part of the IPS e.max Press discs and the whole porcelain thickness still above the set acrylic mold. The embedded discs were then attached to the universal testing machine (Instron Universal testing machine model 3345, England) for the shear bond strength test. A knife edge was adjusted as close as possible to the junction between the ceramic and the porcelain veneer. A cross-head speed of $0.5 \mathrm{~mm} / \mathrm{min}$ was utilized and the maximum load was recorded for each specimen. The nominal shear bond strength was calculated by $\mathrm{P} / \mathrm{A}$, where $\mathrm{P}$ is the load at which fracture occurred and $\mathrm{A}$ is the surface area of the bonding area between the ceramic discs and the porcelain as shown in figure (2)

\section{Microstructure using SEM}

One sample from each group was randomly selected for SEM test to study the microstructure of these samples. Samples were first cleaned then subjected to $9.8 \%$ hydrofluoric acid for 90 seconds, then cleaned in an ultrasonic cleaner, steamed, dried and finally sputter coated with gold. Scanning was performed using SEM (Quanta 250 FEG, Oregon, USA) to examine the microstructure and assess grains of these samples at a magnification of $50000 \mathrm{X}$.

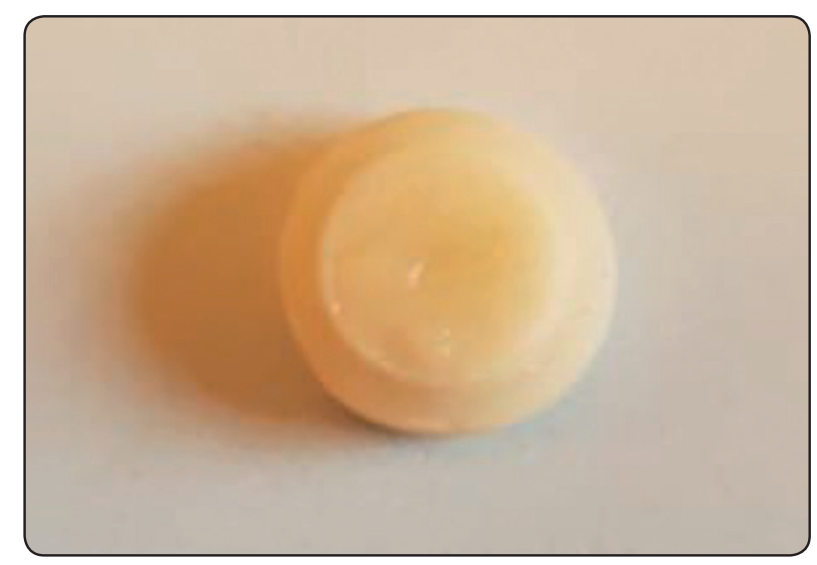

Fig (1): The sample for shear bond strength test 


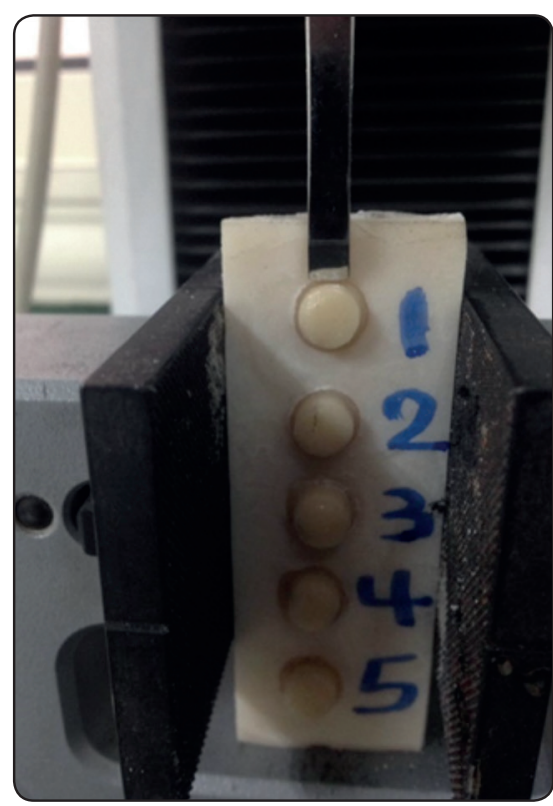

Fig (2): Shear bond strength test

\section{Statistical Tests}

The data from all the tests were collected, tabulated and statistically analyzed using one-way analysis of variance ANOVA followed by a Tukey's HSD test at a significance level of $\mathrm{p}<0.05$.

\section{RESULTS}

\section{Colour Test:}

Results of colour change test $(\Delta \mathrm{E})$ are represented in table 1 and figure (3). The results showed that the $75 \%$ new $+25 \%$ repressed group recorded the least $\Delta \mathrm{E}$ compared to $100 \%$ new group (1.1). The $100 \%$ repressed group showed the highest $\Delta \mathrm{E}$ compared to $100 \%$ new group (3.9). There was a non significant difference between the $75 \%$ new $+25 \%$ re-pressed group and the $50 \%$ new $+50 \%$ re-pressed group, also no significant difference was found between the $25 \%$ new $+75 \%$ re-pressed group and the $100 \%$ re-pressed group. On the other hand, there was a significant difference between both groups the $75 \%$ new $+25 \%$ re-pressed group and the $50 \%$ new $+50 \%$ re-pressed group from one side and both groups $25 \%$ new $+75 \%$ re-pressed and the $100 \%$ re-pressed from the other side.

All $\Delta \mathrm{E}$ of the tested group were in the clinical accepted range except the $100 \%$ re-pressed group.

\section{Translucency test :}

Results of contrast ratio (CR) recorded are represented in table 2 and figure (4). The results showed that the $100 \%$ new group recorded the lowest CR (0.5796). While the $100 \%$ re-pressed group showed the highest CR (0.5924). There was no significant difference between all tested groups as related to translucency

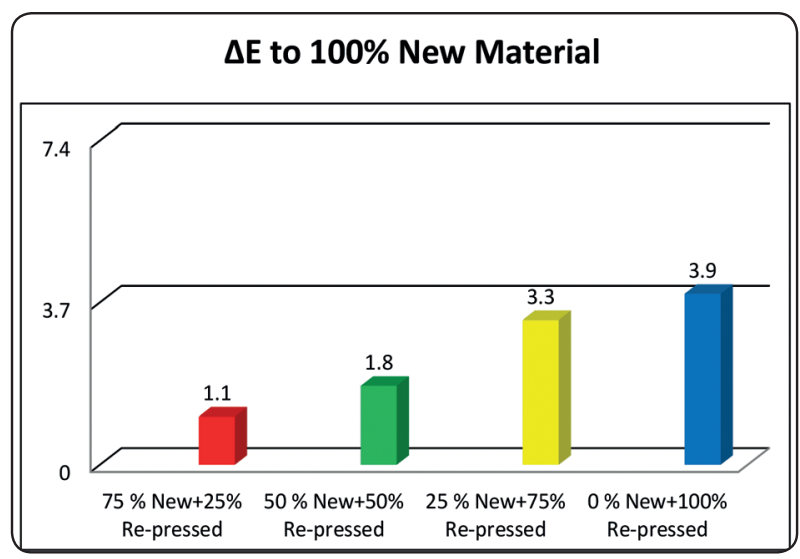

Fig (3): Comparison between $\Delta \mathrm{E}$ between the tested groups and the $100 \%$ new ingot

TABLE (1) $\triangle E$ between the tested groups and the $100 \%$ new ingot

\begin{tabular}{|c|c|c|c|c|}
\hline Groups & $\begin{array}{c}75 \% \text { New }+25 \% \\
\text { Re-pressed }\end{array}$ & $\begin{array}{c}50 \% \text { New }+50 \% \\
\text { Re-pressed }\end{array}$ & $\begin{array}{c}25 \% \text { New }+75 \% \\
\text { Re-pressed }\end{array}$ & $\begin{array}{c}0 \% \text { New }+100 \% \\
\text { Re-pressed }\end{array}$ \\
\hline$\Delta \mathrm{E}($ Mean) & $1.1^{\mathrm{a}}$ & $1.8^{\mathrm{a}}$ & $3.3^{\mathrm{b}}$ & $3.9^{b}$ \\
\hline S.D. & 0.4 & 0.6 & 0.6 & 0.8 \\
\hline
\end{tabular}

*Different letters denote significant difference 


\section{Shear bond strength test:}

Results of shear bond strength test recorded in $\mathrm{MPa}$ are represented in table 3 and figure (5). The results showed that the $100 \%$ new group recorded the highest shear bond strength (29.433 MPa). While the $100 \%$ repressed group showed the least shear bond strength (14.058 MPa). There was no significant difference between $100 \%$ new group and the $75 \%$ new $+25 \%$ repressed group. Also, no significant difference was recorded between the $75 \%$ new $+25 \%$ repressed group and the $50 \%$ new $+50 \%$ repressed group. On the other hand, there was a significant difference between the $100 \%$ new group and the $50 \%$ new $+50 \%$ repressed group which was also different than the $25 \%$ new $+75 \%$ repressed group. Finally, there was a significant difference between the $100 \%$ repressed group and the $25 \%$ new $+75 \%$ repressed group.

\section{Scanning Electron Microscope test:}

Microstructure of the tested groups are shown in figures (6-8). These pictures showed a change in the crystals shape and size. As elongations of the crystals were shown in groups of repressed ceramics. Percentage of elongated crystals was consistent with the weight percentage of the repressed ceramics.

TABLE (2) Translucency of the tested groups

\begin{tabular}{|c|c|c|c|c|c|}
\hline Groups & $100 \%$ new & $\begin{array}{c}75 \% \text { new }+25 \% \\
\text { repressed }\end{array}$ & $\begin{array}{c}50 \% \text { new }+50 \% \\
\text { repressed }\end{array}$ & $\begin{array}{c}25 \% \text { new }+75 \% \\
\text { repressed }\end{array}$ & $100 \%$ repressed \\
\hline Means & $0.5796^{\mathrm{a}}$ & $0.5846^{\mathrm{a}}$ & $0.5882^{\mathrm{a}}$ & $0.5897^{\mathrm{a}}$ & $0.5924^{\mathrm{a}}$ \\
\hline S.D. & 0.0007 & 0.0009 & 0.0009 & 0.0008 & 0.0011 \\
\hline
\end{tabular}

*Different letters denote significant difference

TABLE (3) Shear bond strength of the tested groups (MPa)

\begin{tabular}{|c|c|c|c|c|c|}
\hline Groups & $100 \%$ new & $\begin{array}{c}75 \% \text { new }+25 \% \\
\text { repressed }\end{array}$ & $\begin{array}{c}50 \% \text { new }+50 \% \\
\text { repressed }\end{array}$ & $\begin{array}{c}25 \% \text { new }+75 \% \\
\text { repressed }\end{array}$ & $100 \%$ repressed \\
\hline Means & $29.433^{\mathrm{a}}$ & $27.134^{\mathrm{a}, \mathrm{b}}$ & $24.493^{\mathrm{b}}$ & $19.712^{\mathrm{c}}$ & $14.058^{\mathrm{d}}$ \\
\hline S.D. & 3.172 & 2.666 & 4.106 & 2.632 & 2.98 \\
\hline
\end{tabular}

*Different letters denote significant difference

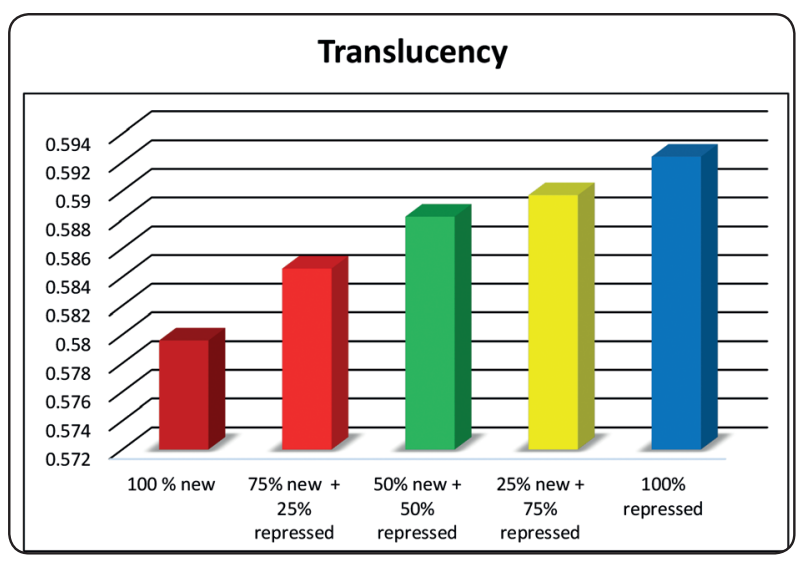

Fig. (4): Comparison between translucency of the tested groups

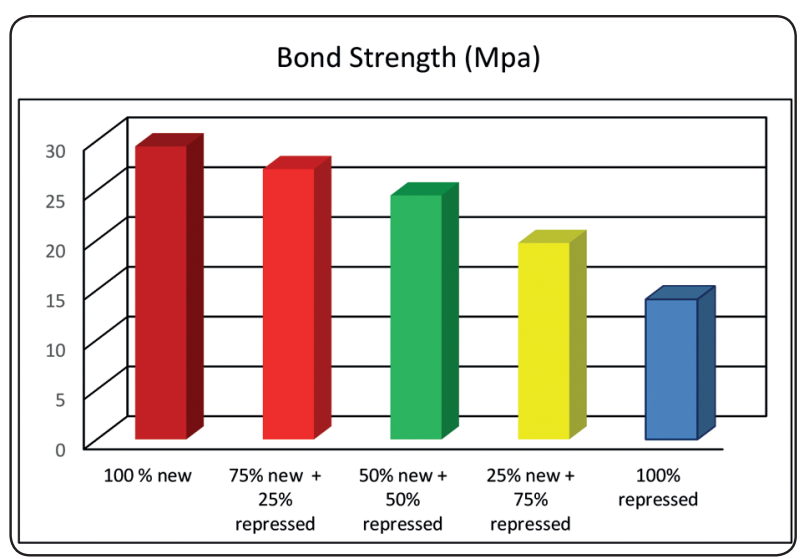

Fig. (5): Comparison between bond strength of the tested groups 


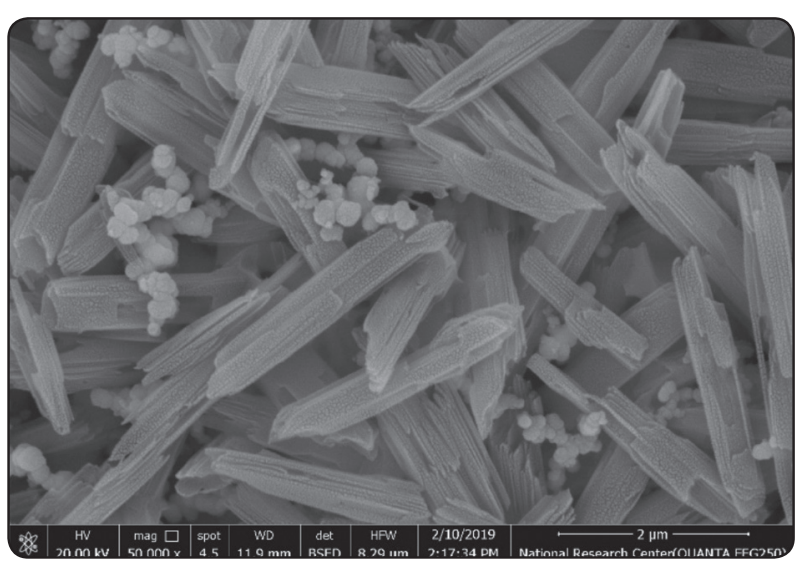

Fig. (6): SEM of $100 \%$ new ceramics

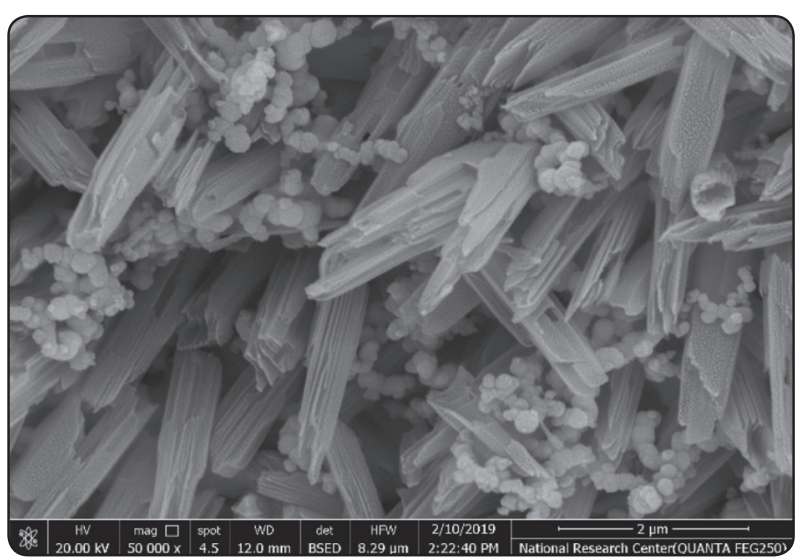

Fig. (7): SEM of 50\% new $+50 \%$ repressed ceramics

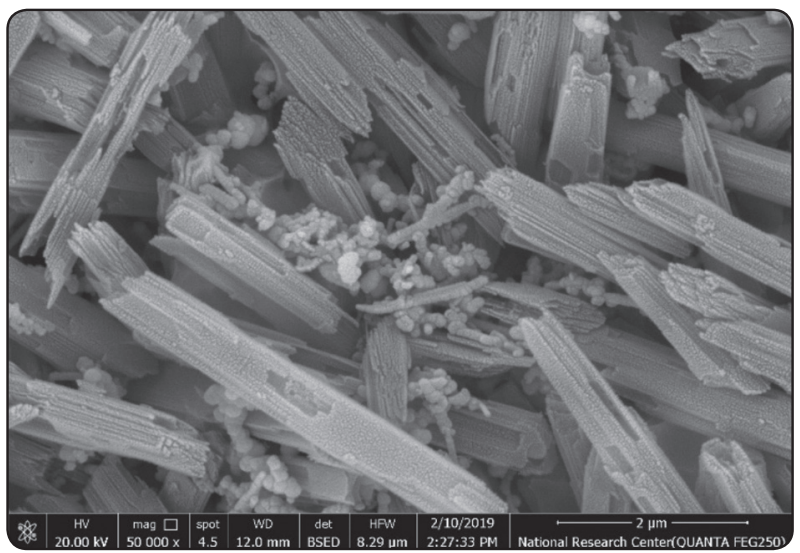

Fig. (8): SEM of $100 \%$ repressed ceramics

\section{DISCUSSION}

In this study IPS e.max Ceram (Ivoclar Vivadent, Schaan, Lichtenstein) was used as recommended by the manufacturer for veneering of IPS e.max lithium disilicate substructures. Ceramic cores and veneering ceramics with compatible CTE are recommended to generate compressive stresses in the weaker veneering ceramics, to reinforce the overall strength of the restorations. ${ }^{(21)}$ IPS e.max Ceram is a lowfusing nano-fluorapatite glass-ceramic that uses an optimized combination of low CTE as well as low firing temperature. These properties rendering it able be applied to all IPS e.max frameworks. To ensure accuracy firing of the veneering ceramic was done in Ivoclar Vivadent furnaces (tolerance range +/$10^{\circ} \mathrm{C} / 18^{\circ} \mathrm{F}$ ) as recommended by the manufacturer as the parameters stated in the instructions for use are coordinated with them and if any other furnaces were used, temperature adjustments might be necessary.

The amount of absorbed, reflected and transmitted light, as well as ceramic type, crystalline volume and particle size compared to the incident wave length affect to great extent colour parameters $\mathrm{L}^{*}$, $a^{*}, b^{*}$, colour saturation and translucency. ${ }^{(14,22-25)}$ These factors influence light diffusion and scattering. Wavelength of visible light is 0.4 to $0.7 \mu \mathrm{m}$. Ceramic materials contain particles of different sizes; larger and smaller than this wavelength. Refraction and reflection occur infinitely on the surfaces of particles that are larger than the wavelength of light thereby causing light to diffuse. ${ }^{(25,26)}$

Translucency is the ability of a layer of coloured substance to allow the appearance of an underlying background to show through. ${ }^{(27)}$ Translucency parameter (TP) or contrast ratio (CR) determine the degree of translucency. ${ }^{(27-29)} \mathrm{TP}$ represents the colour difference between a uniform thickness of a material over a white and a black backing. This is related directly to common visual translucency assessment. $^{(27)} \mathrm{CR}$ is the ratio of the reflectance of 
a material over a black backing to that over a white backing of a known reflectance. It represents opacity estimation of a $1 \mathrm{~mm}$ thick specimen. ${ }^{(28)}$ Translucency of a substance is a function of wavelength. (30) Translucency of a ceramic increases as the size of particles decreases, irregularities in the distribution of the phases, and optical anisotropy of the grains. ${ }^{(25,26,31,32)}$

In the current study the $100 \%$ repressed group showed $\Delta \mathrm{E} 3.9$ which comes in contrary to Zaghloul et al $(\mathbf{2 0 1 3})^{(33)}$, who reported $\Delta \mathrm{E}$ of repressed samples $<3.7$ and considered them matching in the oral cavity. Although, they recorded significant differences in $\mathrm{L}^{*}, \mathrm{a}^{*}, \mathrm{~b}^{*}$ and colour saturation $\mathrm{C}^{*} \mathrm{a}$ $\mathrm{b}$ due to repressing resulting in more yellowish and colourful IPS e.max Press samples. They attributed the colour change to repeated firing and to metal oxides instability during firing affecting the final colour. ${ }^{(34-36)}$

Also, translucency results showed no significant difference between all the tested groups. This comes in accordance with Albakry et al (2004) ${ }^{(3)}$ and Chung et al (2009) $)^{(12)}$, Zaghloul et al $\left(\mathbf{2 0 1 3}^{(33)}\right.$ and El-Etreby (2017) ${ }^{(37)}$. Although there was minimal and insignificant increase in opacity with the increase in percentage of repressed ceramic. This can be attributed to the increase in crystals size due to repressing that may be related to multiple nucleation sites. ${ }^{(12)}$

Albakry et al (2004), ${ }^{(38)}$ as well as El-Etreby \& Ghanem (2017), ${ }^{(39)}$ recorded significant growth of lithium disilicate crystals due to repressing. Tang et al (2014) ${ }^{(1)}$ recorded changes in microstructure of repressed lithium disilicate dental ceramic compared to single press. These changes were in the form of decreased density and increased porosity. Also decreased strength, hardness and toughness Accordingly, they found repeated heat pressing of ceramic unfavourable for clinical cases. The detrimental effect of porosity as denoted by Jones \& Wilson (1975) ${ }^{(40)}$ and Cheung and Darvel (2002), ${ }^{(41)}$ and is due to acting as a stress concentrator and decreasing the cross-sectional area subjected to the applied force. Also, porosity affects the optical properties of the material by scattering light and decreasing translucency. Porosity control is considered as a fundamental consideration in designing or processing of dental ceramics. ${ }^{(41)}$

International Standard of Organization (ISO) standardized the bond strength measurement of a metal ceramic system through the Schiwickerath crack initiation test. The mean debonding strength has to be greater than $25 \mathrm{MPa}$. But due to the all ceramic multi-layered systems brittleness, this test cannot be applied. ${ }^{(6,42)}$ Till now, there is neither a standardized test nor minimum bond strength requirement for an all-ceramic system. ${ }^{(43)}$ According to some authors, SBS values of $10 \mathrm{MPa}$ is considered the minimal value for clinical flaw to occur between metal and ceramic.(44-45) Therefore, SBS values more than $10 \mathrm{MPa}$ indicate accepted bonding clinically. ${ }^{(42,43)}$

Results of the current study showed a significant decrease in bond strength between the $100 \%$ new ceramic group and the $100 \%$ repressed group. Shear bond decreased as the percent of repressed ceramic increases. Although results are clinically accepted, yet this decrease may be related to the change in surface microstructure due to repressing as confirmed by SEM figures (6-8) showing increase in crystals size. Also mixing new ceramic ingot with repressed ceramic improved significantly the bond in comparison to the $100 \%$ repressed group indicating the bond decreases as the weight percent of repressed ceramic increases.

Ting et al (2012), ${ }^{(46)}$ reported that IPS e.max Press recorded the highest SBS values and were significantly different from other tested bi-layered systems even after thermocycling. They attributed these results to core and veneering ceramic effective micromechanical interlocking and chemical bond. They denoted that bond strength can be weakened as result of residual stresses due to veneer and core coefficient of thermal expansion mismatch. ${ }^{(47)}$

The results of this study come in agreement with Gorman et al (2014), ${ }^{(48)}$ who reported that IPS 
e.max Press optimum properties are only obtained with the first pressing.

The hypothesis of the current research was partially rejected as repressing showed a significant difference in colour and bond strength while it showed no significant effect on translucency. Weight percentage of repressed ceramic had an effect on $\Delta \mathrm{E}$, decreasing this percentage resulted in decreasing $\Delta \mathrm{E}$ compared to repressed un-mixed samples while it didn't show significant effect on either colour or translucency of the newly pressed samples. Repressing had a significant effect on bond strength with the veneering material. Also, mixing had a significant effect improving bond strength compared to the purely repressed samples.

\section{CONCLUSIONS}

Within the limitations of this study:

1. The mix of new ingot with repressed ceramic are in the clinical acceptance range as regard $\Delta \mathrm{E}$.

2. $100 \%$ repressed ceramic can affect the final colour.

3. Repressing ceramic have no significant effect on translucency.

4. Repressing ceramic percent have a direct effect upon bond strength as increasing the percentage of repressed ceramic led to a decrease of bond strength values.

\section{REFERENCES}

1. Tang X, Tang C, Su H, Luo H. The effects of repeated heat pressing on the mechanical properties and microstructure of IPS e.max Press. J Mech Behav Biomed Mater. 2014; 40:390-396.

2. Griggs J. Recent in material for all ceramic restorations. Dent Clin North Am. 2007;51(3):713- 727.

3. Albakry M, Guazzato M, Swain MV. Biaxial flexural strength and microstructure changes of two recycled pressable glass ceramics. J Prosthodont. 2004; 13:141-149.

4. Dong J K, Luthy H, Wohlwend A, Scharer P. Heat-pressed ceramics: technology and strength. Int J Prosthodont. 1992; 5:9-16.
5. Gorman CM, McDevitt WE, Hill RG. Comparison of two heat-pressed all-ceramic dental materials. Dent Mater 2000;16: 389-395.

6. Albakry M, Guazzato M, Swain MV. Biaxial flexural strength, elastic moduli, and x-ray diffraction characterization of three pressable all-ceramic materials. J Prosthet Dent 2003; 89:374-380.

7. Guazzato M, Albakry M, Ringer SP, Swain MV. Strength, fracture toughness and microstructure of a selection of all-ceramic materials. Part I. Pressable and alumina glassinfiltrated ceramics. Dent Mater 2004; 20:441-448.

8. Dickerson W, Miyasaki M. The esthetic revolution continues-IPS Empress. J Oral Health. 1999; 2:87-90.

9. Probster L, Geis-Gerstorfer J, Kirchner E, Kanjantra P. In vitro evaluation of a glass ceramic restorative material. J Oral Rehabil 1997; 24:636-645.

10. Scientific documentation. Lithium disilicate. 2011; Ivoclar Vivadent AG. Available from: http://www.ivoclarvivadent.

11. Stanton K T. Effects of repeated processing on the strength and microstructure of a heat-pressed dental ceramic. J Prosthet Dent 2014; 112: 1370-1376.

12. Chung KH, Liao JH, Duh JG, Chan DC. The effects of repeated heat-pressing on properties of pressable glass ceramics. J Oral Rehabil. 2009; 36:132-141.

13. Salem SK, Shalaby MM. Fracture strength and marginal gap of re-pressed IPS e.max Press crowns with different concentrations. EDJ. 2019; 65:853-862.

14. Seghi RR, Johnston WM, and O'Brien WJ: Spectrophotometric analysis of color differences between porcelain systems . J Prosthet Dent.1986; 56:35-40

15. Aboushady Y: Colour changes after surface polishing of high and low fusing ceramometal systems. E D J.2001; 47:89.

16. Johnston WM, Kao EC. Assessment of appearance match by visual observation and clinical colorimetry. J Dent Res.1989; 68:819.

17. Mohsen SA. Effect of finishing technique \& accelerated aging on the color \& chemical durability of two pressable ceramics. EDJ. 2010; 56: 711-720.

18. Vadher R, Parmar G, Kanodia S, Chaudhary A, Kaur M, Savadhariya T. Basics of Color in Dentistry: A Review. IOSR-JDMS. 2014;13: 78-85.

19. Anusavice KJ, Ringle RD, Fairhurst CW. Adherence controlling elements in ceramic-metal systems. II. Nonprecious alloys. J Dent Res. 1977; 56:1053-1061. 
20. López-Mollá MV, Martínez-González MA, Mañes-Ferrer JF, Amigó- Borrás V, Bouazza-Juanes K. Bond strength evaluation of the veneering-core ceramics bonds. Med Oral Patol Oral Cir Bucal. 2010 Nov 1;15(6): e919-23

21. Scientific Documentation IPS e.max Press.2011. Ivoclar Vivadent AG. Available from: http://www.ivoclarvivadent.

22. O'Brien WJ, Kay KS, Boenke KM, Groh cL. Sources of color variation on firing porcelain. Dent Mater. 1991;7: 170-173.

23. Hammad IA, Stein RS. A qualitative study for the bond and color of ceramometals. Part II. J Prosthet Dent. 1991; 97:25-31.

24. Orchard VN: Introduction to dental materials ( $\left.2^{\text {nd }} . e d\right) . S T$. Louis, Elsevier.2002; pp235-236.

25. Heffernan MJ, Aquilino SA, Diaz-Arnold AM. Haselton DR, Stanford CM, Vargas MA. Relative translucency of six all-ceramic systems. Part III: core and veneer materials. J Prosthet Dent. 2002; 88:10-15.

26. Heffernan MJ, Aquilino SA, Diaz-Arnold AM. Haselton DR, Stanford CM, Vargas MA. Relative translucency of six all-ceramic systems. Part I: core and materials. J Prosthet Dent. 2002; 88:4-9.

27. Johnston WM, Ma T, Kienle BH. Translucency parameter of colorants for maxillofacial prostheses. Int J Prosthodont. 1995; 8:79-86.

28. Miyagawa Y, Powers JM, O'Brien WJ. Optical properties of direct restorative materials. J Dent Res 1981; 60:890-894.

29. Powers JM, Sakaguchi RL. Restorative dental materials, $12^{\text {th }}$ ed. St. Louis, Mo.: Mosby; 2006.

30. Brodbelt RH, O’Brien WJ, Fan PL, Frazer-Dib JG, Yu R. Translucency of human dental enamel. J Dent Res 1981;60: 1749-1753.

31. Bahgat S F, Ramadan R B, El Sayed S M. Effect of zirconia addition to lithium disilicate ceramic on translucency and bond strength using different adhesive strategies. E.D.J. 2015; 61, No. 4: 4519-4533.

32. Yu B, Ahn J, Lee Y. Measurement of translucency of tooth enamel and dentin. Acta Odontol Scand. 2009; 67: 57-64.

33. Zaghloul HH, Halim C, Ghanim LA. Effect of repeated heat pressing on color, translucency and surface quality of pressable ceramics. EDJ.2013;59:2913-2930.

34. Crispin BJ, Seghi RR, Globe H. Effect of different metal ceramic alloys on color of opaque and dentin porcelain. J Prosthet Dent. 1991; 65:351-356.
35. Mulla FA, Weiner S. Effects of temperatures on color stability of porcelain stains. J Prosthey Dent. 1991; 65:507-512.

36. Lund PS, Piotrowski TJ. Color changes of porcelain surface colorants resulting from firing. Int J Prosthodont. 1992; 5:22-27.

37. El-Etreby AS. Effect of repressing and glazing on color reproduction, translucency and surface roughness of lithium disilicate glass-ceramics. EDJ.2017; 63: 79-88.

38. Albakry M, Guazzato M, Swain M V. Influence of Hot Pressing on the Microstructure and Fracture Toughness of Two Pressable Dental Glass-Ceramics. J Biomed Mater Rers Part B: Appl Biomater. 2004; 71B:99-107.

39. El-Etreby AS, Ghanem L. The effect of repeated heat-pressing on the biaxial flexural strength and surface roughness of lithium disilicate glass ceramics. EDJ. 2017; 63:53-60.

40. Jones DW, Wilson HJ. Porosity in dental ceramics. Br Dent J. 1975; 138:16-21.

41. Cheung KC, Darvell BW. Sintering of dental porcelain: effect of time and temperature on appearance and porosity. Dent Mater 2002; 18:163-173.

42. Tarib N A, Anuar N, Ahmad M. Shear bond strength of veneering ceramic to coping materials with different presurface treatments. J Adv Prosthodont 2016; 8:339-344

43. Al-Dohan HM, Yaman P, Dennison JB, Razzoog ME, Lang BR. Shear strength of core-veneer interface in bi-layered ceramics. J Prosthet Dent 2004; 91:349-355.

44. Anusavice KJ. Noble metal alloys for metal-ceramic restorations. Dent Clin North Am 1985; 29:789-803.

45. Hammad IA, Talic YF. Designs of bond strength tests for metal-ceramic complexes: review of the literature. J Prosthet Dent 1996; 75:602-608.

46. Ting S, Lonquan S, Bin D Ning W. Shear bond strengths between ceramic cores and veneering ceramics of dental bi-layered ceramic systems and the sensitivity to thermocycling. Ceram-Silik. 2012; 56 (3): 238-244.

47. Aboushelib MN, de Jager N, Kleverlaan CJ, Feilzer AJ. Microtensile bond strength of different components of core veneered all ceramic restorations. Dent. Mater. 2005; 21: 984- 991.

48. Gorman CM, Horgan K, Dollard RP, Stanton KT. Effects of repeated processing on the strength and microstructure of a heat-pressed dental ceramic. J Prosthet Dent. 2014; 112(6):1370-1376. 